\title{
Associations between meal and snack frequency and diet quality and adiposity measures in British adults: findings from the National Diet and Nutrition Survey
}

\author{
Kentaro Murakami ${ }^{1, *}$ and M Barbara E Livingstone ${ }^{2}$ \\ 'Department of Nutrition, School of Human Cultures, University of Shiga Prefecture, Hikone, Shiga 522 8533, \\ Japan: ${ }^{2}$ Northern Ireland Centre for Food and Health, Ulster University, Coleraine, UK
}

Submitted 6 July 2015: Final revision received 24 August 2015: Accepted 15 September 2015: First published online 16 October 2015

\begin{abstract}
Objective: To examine how different definitions of meals and snacks can affect the associations of meal frequency (MF) and snack frequency (SF) with dietary intake and adiposity measures.

Design: Based on $7 \mathrm{~d}$ weighed dietary record data, all eating occasions providing $\geq 210 \mathrm{~kJ}$ of energy were divided into meals or snacks based on contribution to energy intake $(\geq 15 \%$ or $<15 \%)$ or time $(06.00-10.00,12.00-15.00$ and 18.00-21.00 hours; other). Diet quality was assessed using the Healthy Diet Indicator (HDI) and Mediterranean Diet Score (MDS).

Setting: Great Britain.

Subjects: British adults aged 19-64 years ( $n$ 1487).

Results: MF based on energy contribution was associated with higher intake of dietary fibre, lower intakes of non-milk extrinsic sugars and alcohol, and higher HDI (only men) and MDS. MF based on time was associated with higher HDI and MDS in women only. Conversely, irrespective of the definition of snacks, SF was associated with higher intakes of confectionery and alcohol, lower intakes of cereals, protein, fat and dietary fibre, and lower HDI (except for SF based on energy contribution in women) and MDS. After adjustment for potential confounders, MF based on time, but not MF based on energy contribution, was positively associated with BMI and waist circumference in men only. SF was positively associated with BMI and waist circumference, irrespective of the definition of snacks.

Conclusions: Higher SF was consistently associated with lower diet quality and higher adiposity measures, while associations with MF varied depending on the definition of meals and sex.
\end{abstract}

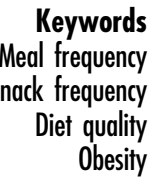

Many epidemiological studies have investigated the association between eating frequency (EF) and adiposity measures, but the results are highly inconsistent with a mixture of inverse ${ }^{(1-7)}$, null ${ }^{(8-13)}$ and positive ${ }^{(14-20)}$ associations. The associations between EF and food and nutrient intakes are equally inconclusive $e^{(2,6,7,15,21-23)}$. This is an issue that is beset by substantial methodological problems. First, while the assessment of EF has often relied on a series of non-validated, self-report questions $^{(2,5-7,11,14,15,18,19)}$, only a few studies have directly assessed EF on the basis of actual dietary habits (using a dietary record or $24 \mathrm{~h}$ recall) ${ }^{(1,4,9,10,20)}$. Second, the association of EF with adiposity measures (as well as dietary intake) may be confounded by possible underreporting of $\mathrm{EF}$ concomitant with the under-reporting of energy intake (EI) by obese or overweight subjects ${ }^{(21,22)}$.
In fact, a very limited number of studies ${ }^{(16,17,19,20)}$, but not all ${ }^{(1,3,6,10,12,13)}$, suggest that $\mathrm{EF}$ is positively, rather than inversely, associated with adiposity measures after accounting for EI reporting bias. Third, interpreting the literature on EF is complicated by the fact that there is no consensus about what constitutes a snack, a meal or an eating occasion. While some researchers have relied on respondents' self-identification of meals, snacks or eating occasions $^{(2,5-7,11-15,18)}$, others have attempted to use more

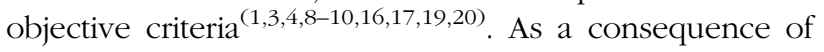
these methodological limitations, the discrepant findings are not surprising, and severely impede clarification of the impact of EF on diet quality and adiposity status.

More importantly, potentially different effects of meal frequency (MF) and snack frequency (SF) have not been investigated simultaneously using different definitions of 
meals and snacks. An accurate distinction between meals and snacks is important, because they are hypothesized to have opposite effects on energy balance. A high MF may prevent fat mass deposition, while snacking may contribute to it ${ }^{(24)}$. This is also important for the development of science-based recommendations (of snacking) for consumers $^{(25)}$. Moreover, in the absence of a universally accepted definition of meals and snacks, an understanding of the influence of different meal and snack definitions on the associations with diet quality and adiposity may facilitate the interpretation of the existing literature and help establish consensus on the most appropriate research definition for meals and snacks ${ }^{(23)}$.

The aim of the present cross-sectional study in British adults was to examine the relationship of MF and SF with food and nutrient intakes, diet quality, BMI and waist circumference (WC), by focusing on the confounding of EI misreporting and the use of different definitions of meals and snacks.

\section{Methods}

\section{Survey design}

The current cross-sectional study was based on the National Diet and Nutrition Survey (NDNS): Adults Aged 19 to 64 Years. Details of the rationale, design and methods of the survey have been described elsewhere ${ }^{(26)}$. Briefly, the sample was randomly selected from 152 randomly selected postal sectors within mainland Great Britain. Eligibility was defined as being aged 19-64 years and not pregnant or breast-feeding. One eligible adult per private household was selected at random. Data collection was conducted from July 2000 to June 2001.

\section{Anthropometric measurements}

All anthropometric measurements were performed in duplicate by trained fieldworkers and the mean value of two measurements was used in the analysis. Height (to the nearest $0.1 \mathrm{~cm}$ ) and weight (to the nearest $0.1 \mathrm{~kg}$ ) were measured while participants were barefoot and wearing light clothes only. BMI $\left(\mathrm{kg} / \mathrm{m}^{2}\right)$ was calculated as weight (in kilograms) divided by height (in metres) squared. WC was measured at the midpoint between the iliac crest and the lower rib (to the nearest $0 \cdot 1 \mathrm{~cm}$ ).

\section{Dietary assessment}

Dietary data were collected by a $7 \mathrm{~d}$ weighed dietary record. A detailed description of the procedure has been published elsewhere ${ }^{(26,27)}$. Briefly, each participant was supplied with a set of digital food scales and recording diaries. The participant was given by trained interviewers both written and verbal instructions on how to weigh and record items in the diary. When weighing was not possible (e.g. eating out; $47 \%$ of total food items recorded), the participant was asked to record as much information as possible. Trained interviewers visited the household at least twice during the recording period and checked the completeness of food recording. All the collected diaries were checked by trained nutritionists in terms of coding, recorded weights and descriptions of items consumed. Estimates of daily intakes of foods, energy and selected nutrients were calculated based on the Food Standards Agency nutrient databank ${ }^{(28)}$, which is based on McCance E Widdowson's The Composition of Foods series ${ }^{(29)}$ and manufacturers' data where applicable. For all dietary variables, mean daily values over $7 \mathrm{~d}$ were used in the analysis. Values of food and nutrient intakes were energyadjusted using the density method (i.e. percentage of energy for energy-providing nutrients and amount per $10 \mathrm{MJ}$ of energy for foods and other nutrients).

As measures of diet quality, the Healthy Diet Indicator (HDI) and the Mediterranean Diet Score (MDS) were calculated (see online supplementary material, Supplemental Table 1). The HDI includes six nutrients and one food group (saturated fat, polyunsaturated fat, cholesterol, protein, dietary fibre, fruits and vegetables, and non-milk extrinsic sugars) ${ }^{(30,31)}$. When intake was within the recommended range according to WHO guidelines, a score of 1 was assigned to that component; otherwise, a score of 0 was assigned, with a total score ranging from 0 to 7 . Hence, a higher score reflected a healthier dietary pattern. The MDS represents a Mediterranean-type diet and is based on the consumption of nine different components (vegetables; legumes; fruits, nuts and seeds; cereals; fish; ratio of unsaturated to saturated fats; meat; dairy products; and alcohol) ${ }^{(31,32)}$. A score of 1 was assigned to moderate alcohol intake or, depending on the component, intake above or below the sex-specific median. Scores for all nine components were summed and resulted in a total range from 0 to 9, whereby a higher score reflected better adherence to a Mediterranean-type diet.

\section{Definition of eating frequency, meal frequency and snack frequency}

Data from the $7 \mathrm{~d}$ dietary record were also used to calculate the average number of eating occasions per day; that is, EF. Eating occasions were defined as any occasion when any food or drink was consumed ${ }^{(12,13,17,20)}$. If two eating occasions occurred in $\leq 15 \mathrm{~min}$, both events were counted as a single eating occasion; when $>15$ min separated two eating occasions, these were considered distinct eating occasions ${ }^{(1,4,10,17,20)}$. EF was calculated based on all eating occasions except for those providing $<210 \mathrm{~kJ}$ of energy. This calculation method has been used in several previous studies ${ }^{(4,12,13,17,20)}$ and was chosen to avoid giving undue weight to eating occasions that only included water, low-calorie beverages or small quantities of foods. In the present study, the mean contribution of eating occasions providing $<210 \mathrm{~kJ}$ to total EI was $2 \cdot 0$ (SD 2.2) \% in men and 3.1 (SD 3.0) \% in women. 
All eating occasions were divided into either meals or snacks with the use of two different published definitions: on the basis of (i) contribution to total $\mathrm{EI}^{(33)}$ and (ii) clock time $^{(34)}$. For the first definition ${ }^{(33)}$, a meal was defined as any eating episode comprising $\geq 15 \%$ of total EI, regardless of the time of day or composition of foods or beverages consumed. All other eating episodes were classified as a snack. For each participant, MF and SF determined based on energy contribution were calculated (hereafter referred to as $\mathrm{MF}_{\text {energy\% }}$ and $\mathrm{SF}_{\text {energy\%, }}$, respectively). For the second definition ${ }^{(34)}$, meals were defined as eating events reported during selected times of the day; that is, 06.00-10.00, 12.00-15.00 and 18.00-21.00 hours. All other eating occasions were considered snacks. For each participant, $\mathrm{MF}$ and SF determined based on time were calculated (hereafter referred to as $\mathrm{MF}_{\text {time }}$ and $\mathrm{SF}_{\text {time, }}$, respectively). It should be noted that no self-definition of eating occasions was included in the NDNS dietary record.

\section{Assessment of non-dietary variables}

The socio-economic status of each participant (i.e. occupational social class) was self-reported and categorized as manual or non-manual. Smoking status (never, former or current) was also self-reported. A $7 \mathrm{~d}$ physical activity diary was carried out concurrently with the dietary record. A detailed description of the procedure has been published elsewhere ${ }^{(26,27)}$. Briefly, the participant was shown by trained interviewers how to record the information and was asked to record, to the nearest $10 \mathrm{~min}$, how long they spent doing various activities on that day. Trained interviewers checked the completeness of records at least twice during the recording period. Subsequently, time spent daily in sleep, light-, moderateand vigorous-intensity activities was computed for each day of recording. The number of hours spent per day on each activity was multiplied by the metabolic equivalent of task (MET) value of that activity (derived from a published table) ${ }^{(35)}$ and all MET-h products were summed to produce a total MET-h score for the day. A mean daily value over $7 \mathrm{~d}$ was used in the analysis. We calculated each participant's estimated energy requirement (EER) with the use of equations published from the US Dietary Reference Intakes ${ }^{(36)}$. Physical activity category was determined for each participant based on the physical activity level calculated as total MET-h/d (from the $7 \mathrm{~d}$ physical activity diary) divided by 24 . As a measure of dietary misreporting, the ratio EI:EER was then calculated. Participants were identified as acceptable reporters, under-reporters or over-reporters of EI based on their EI:EER, according to whether the individual's ratio was within, below or above the $95 \%$ confidence limits of the expected ratio of $1 \cdot 0$. Based on a published equation ${ }^{(16)}$, acceptable reporters were defined as having EI:EER in the range 0.665 to 1.335, under-reporters as EI:EER $<0.665$ and over-reporters as EI:EER $>1 \cdot 335$. A detailed description of the procedure has been published elsewhere ${ }^{(20,27)}$.

\section{Analytic sample}

Of 3704 potentially eligible individuals identified for the study, 2251 (61\% of eligible sample) participated in the survey. For the present analysis, we excluded a total of 736 individuals with missing information on the variables used. We further excluded twenty-eight underweight individuals $\left(\mathrm{BMI}<18.5 \mathrm{~kg} / \mathrm{m}^{2}\right)^{(37)}$. The final analysis sample comprised 1487 adults aged 19-64 years (678 men and 809 women; $40 \%$ of the eligible sample). Further exclusion of individuals who reported dieting or that illness had affected their eating during the diet recording period ( $n$ 397) did not alter the findings of the present study (data not shown); therefore, these participants were included in the analysis.

\section{Statistical analysis}

All statistical analyses were performed for men and women separately, using the statistical software package SAS version 9.2. Associations between various measures of MF and SF as well as those of MF and SF with EI:EER and EI were investigated through Pearson correlation analyses. Associations of MF and SF with food and nutrient intakes and measures of diet quality were investigated by linear regression analyses using the PROC REG procedure, with adjustment for age, social class and EI:EER. Linear regression analyses were also performed to explore the associations of MF and SF with BMI and WC. With the use of the PROC REG procedure, we calculated the crude (i.e. model 1) and adjusted (i.e. models 2 and 3) regression coefficients (with $\mathrm{SE}$ ) of variation of $\mathrm{BMI}$ and WC by one increase of MF and SF. Potential confounding factors included in the multivariate models (model 2) were age, social class, smoking status, physical activity, and intakes of protein, fat, total sugar, alcohol and dietary fibre. We further included EI:EER as a potential confounding factor (model 3). We decided to adjust for EI:EER in multivariate models, rather than excluding EI under-reporters and over-reporters from the analysis, because the differences in basic characteristics between under-reporters and acceptable reporters observed in the present population ${ }^{(20,27)}$ suggested that data exclusion may actually introduce a selection bias. This approach has been used in several previous studies ${ }^{(38-41)}$. MF and SF were analysed continuously after confirming the linearity of relationships using tertile, quartile and quintile categories.

Data have not been weighted to take into account known sociodemographic differences between responders and non-responders, not only because the impact of this adjustment, applied as a weighting factor, for nutritional variables was extremely small and not significant ${ }^{(26)}$ but also because we were only interested in relationships between variables, rather than estimates of prevalence ${ }^{(20,27)}$. All reported $P$ values are two-tailed and $P$ values of $<0.05$ were considered statistically significant. 


\section{Results}

The mean values of $\mathrm{BMI}$ and WC were, respectively, $27.3 \mathrm{~kg} / \mathrm{m}^{2}$ and $96.0 \mathrm{~cm}$ in men and $26.8 \mathrm{~kg} / \mathrm{m}^{2}$ and $83.1 \mathrm{~cm}$ in women (Table 1 ). The percentage of acceptable reporters and under-reporters of EI were $63 \%$ and $37 \%$ in men and $55 \%$ and $45 \%$ in women, respectively (only three men (0.4\%) were classified as over-reporters). In both men and women, compared with acceptable reporters, under-reporters had a lower mean value of age and EI and a higher mean value of physical activity, BMI and WC (data not shown). They were also more likely to be employed in manual occupations and be current smokers (data not shown).

The mean value of $\mathrm{MF}_{\text {energy\% }}$ was significantly $(P<0 \cdot 0001)$ lower than that of $\mathrm{MF}_{\text {time }}$ in both men $(2 \cdot 29 v$. 3.64 times/d) and women (2.28v. 3.28 times/d; Table 2). While there was no correlation between $\mathrm{MF}_{\text {energy\% }}$ and $\mathrm{MF}_{\text {time }}$ in men, $\mathrm{MF}_{\text {energy\% }}$ was weakly correlated with $\mathrm{MF}_{\text {time }}$ in women. The mean value of $\mathrm{SF}_{\text {energy } \% \text { was }}$ significantly $(P<0.0001)$ higher than that of $\mathrm{SF}_{\text {time }}$ in both men (3.32 v. 1.97 times/d) and women (2.56 v. 1.57 times/d). There were strong correlations between both measures of SF in both men and women. While $\mathrm{MF}_{\text {energy } \%}$ showed an inverse association with EF in men and no association with EF in women, there were strong correlations of $\mathrm{MF}_{\text {time, }}, \mathrm{SF}_{\text {energy\% }}$ and $\mathrm{SF}_{\text {time }}$ with $\mathrm{EF}$ in both sexes. All measures of $\mathrm{MF}$ and $\mathrm{SF}$ were significantly positively correlated with both EI:EER and EI in both men and women (Table 3).

Tables 4 and 5 show the associations of MF and SF with dietary characteristics in men and women, respectively. Generally speaking, the associations for MF varied depending on the definition of meals and sex. $\mathrm{MF}_{\text {energy\% }}$ showed positive associations with cereals, vegetables (only women), fruits (only men), starch and dietary fibre, and inverse associations with alcoholic beverages, meat

Table 1 Characteristics of participants; British adults aged 19-64 years (n 1487), National Diet and Nutrition Survey, 2000-2001

\begin{tabular}{|c|c|c|c|c|}
\hline & \multicolumn{2}{|c|}{ Men ( $n$ 678) } & \multicolumn{2}{|c|}{ Women ( $n$ 809) } \\
\hline & $\begin{array}{c}\text { Mean or } \\
\%\end{array}$ & SD & $\begin{array}{c}\text { Mean or } \\
\%\end{array}$ & SD \\
\hline Age (years) & $42 \cdot 4$ & $12 \cdot 0$ & $42 \cdot 4$ & 11.9 \\
\hline \multicolumn{5}{|l|}{ Social class (\%) } \\
\hline Manual & $46 \cdot 2$ & - & $32 \cdot 4$ & - \\
\hline Non-manual & $53 \cdot \overline{8}$ & - & $67 \cdot 6$ & - \\
\hline \multicolumn{5}{|l|}{ Smoking status (\%) } \\
\hline Never & 44.3 & - & $46 \cdot 7$ & - \\
\hline Former & 25.4 & - & 21.6 & - \\
\hline Current & 30.4 & - & 31.6 & - \\
\hline Physical activity (MET-h/d) & $46 \cdot 1$ & $10 \cdot 2$ & $42 \cdot 3$ & $4 \cdot 1$ \\
\hline $\mathrm{BMI}\left(\mathrm{kg} / \mathrm{m}^{2}\right)$ & $27 \cdot 3$ & 4.4 & 26.8 & 5.6 \\
\hline WC $(\mathrm{cm})$ & 96.0 & 11.0 & 83.1 & 11.9 \\
\hline $\mathrm{El}(\mathrm{kJ} / \mathrm{d})$ & 9837 & 2523 & 6932 & 1769 \\
\hline El:EER & 0.73 & 0.19 & 0.69 & 0.18 \\
\hline
\end{tabular}

MET, metabolic equivalent of task; WC, waist circumference; El, energy intake; EER, estimated energy requirement.

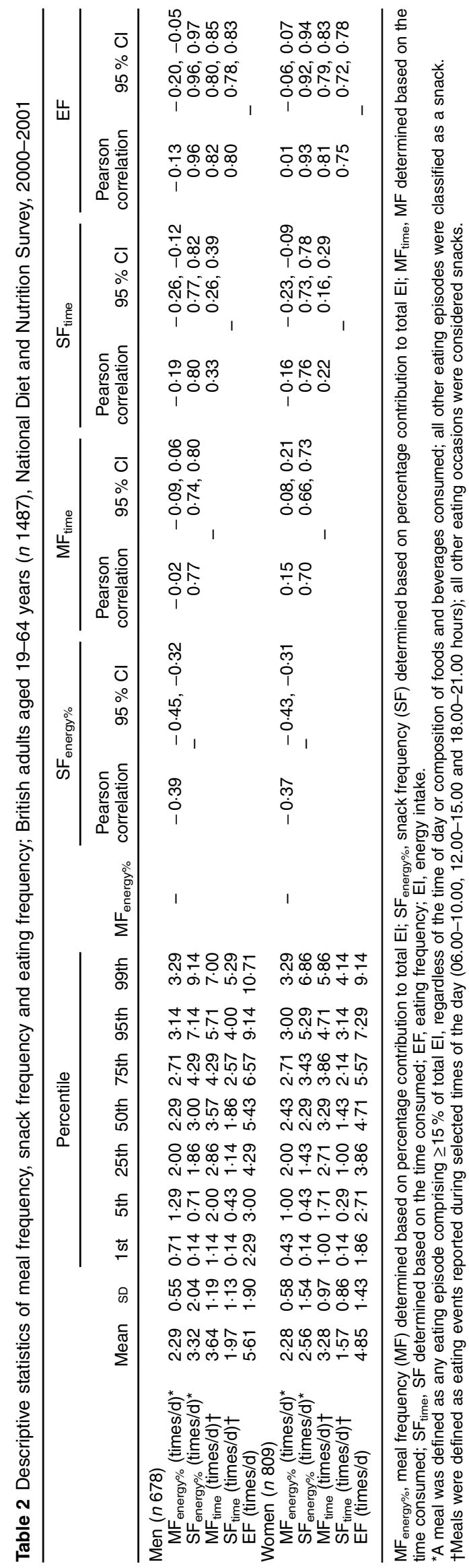


Table 3 Correlation of meal frequency and snack frequency with El:EER and El; British adults aged $19-64$ years ( $n$ 1487), National Diet and Nutrition Survey, 2000-2001

\begin{tabular}{|c|c|c|c|c|c|c|c|c|}
\hline & \multicolumn{4}{|c|}{ Men $(n$ 678) } & \multicolumn{4}{|c|}{ Women ( $n$ 809) } \\
\hline & \multicolumn{2}{|c|}{ El:EER } & \multicolumn{2}{|c|}{$\mathrm{EI}(\mathrm{kJ} / \mathrm{d})$} & \multicolumn{2}{|c|}{ El:EER } & \multicolumn{2}{|c|}{$\mathrm{EI}(\mathrm{kJ} / \mathrm{d})$} \\
\hline & $\begin{array}{l}\text { Pearson } \\
\text { correlation }\end{array}$ & $95 \% \mathrm{Cl}$ & $\begin{array}{l}\text { Pearson } \\
\text { correlation }\end{array}$ & $95 \% \mathrm{Cl}$ & $\begin{array}{l}\text { Pearson } \\
\text { correlation }\end{array}$ & $95 \% \mathrm{Cl}$ & $\begin{array}{l}\text { Pearson } \\
\text { correlation }\end{array}$ & $95 \% \mathrm{Cl}$ \\
\hline $\mathrm{MF}_{\text {energy } \%}(\text { times } / \mathrm{d})^{\star}$ & 0.17 & $0.09,0.24$ & 0.15 & $0.08,0.22$ & 0.16 & $0.09,0.22$ & 0.18 & $0.12,0.25$ \\
\hline $\mathrm{SF}_{\text {energy\% }}(\text { times } / \mathrm{d})^{\star}$ & 0.44 & $0.37,0.50$ & 0.45 & $0.39,0.51$ & 0.48 & $0.43,0.53$ & 0.46 & $0.40,0.51$ \\
\hline $\mathrm{MF}_{\text {time }}($ times $/ \mathrm{d}) \dagger$ & 0.45 & $0.38,0.51$ & 0.46 & $0.40,0.51$ & 0.50 & $0.44,0.55$ & 0.47 & $0.41,0.52$ \\
\hline $\mathrm{SF}_{\text {time }}($ times $/ \mathrm{d}) \dagger$ & 0.40 & $0.33,0.46$ & 0.41 & $0.34,0.47$ & 0.41 & $0.35,0.47$ & 0.42 & $0.36,0.47$ \\
\hline
\end{tabular}

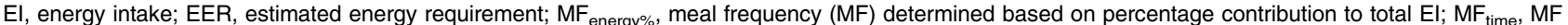
determined based on the time consumed; $\mathrm{SF}_{\text {energy\%, }}$ snack frequency (SF) determined based on percentage contribution to total El; $\mathrm{SF}$ time, $\mathrm{SF}_{\text {determined }}$ based on the time consumed.

${ }^{*} \mathrm{~A}$ meal was defined as any eating episode comprising $\geq 15 \%$ of total El, regardless of the time of day or composition of foods and beverages consumed; all other eating episodes were classified as a snack.

†Meals were defined as eating events reported during selected times of the day (06.00-10.00, 12.00-15.00 and 18.00-21.00 hours); all other eating occasions were considered snacks.

(only men), confectionery (only men) and non-milk extrinsic sugars. However, $\mathrm{MF}_{\text {time }}$ was associated positively with dairy products, confectionery, alcoholic beverages, vegetables (only women), fruits (only women), soft drinks (only women) and non-milk extrinsic sugars, and inversely with cereals, legumes (only men), fish (only men), meat (only women), total, saturated, monounsaturated and polyunsaturated fats, and starch. Dietary fibre was inversely associated with $\mathrm{MF}_{\text {time }}$ in men but showed a positive association in women. For measures

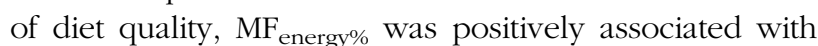
MDS in both sexes and with HDI in only men, while $\mathrm{MF}_{\text {time }}$ showed positive associations with both MDS and HDI in only women. In contrast, both $\mathrm{SF}_{\text {energy\% }}$ and $\mathrm{SF}_{\text {time }}$ were generally associated with unfavourable dietary intake patterns in both sexes, including higher intakes of confectionery, alcoholic beverages, soft drinks (only women) and non-milk extrinsic sugars, and lower

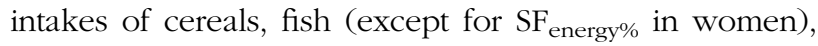
vegetables (except for $\mathrm{SF}_{\text {energy\% }}$ in women), protein, monounsaturated and polyunsaturated fats, starch and dietary fibre. There were also inverse associations between $\mathrm{SF}_{\text {energy\% }}$ and $\mathrm{SF}_{\text {time }}$ and measures of diet quality in both sexes, except for no association between $\mathrm{SF}_{\text {energy\% }}$ and HDI in women.

The associations of MF and SF with adiposity measures are presented in Table 6. In the univariate analyses (model 1), all measures of MF and SF showed inverse or null associations with BMI and WC in both men and women. Adjustment for age, social class, smoking status, physical activity and intakes of protein, fat, total sugar, alcohol and dietary fibre (model 2) revealed no associations for all measures of MF and SF, except for inverse associations for $\mathrm{MF}_{\text {time }}$ in women. Further adjustment for EI:EER (model 3) resulted in positive associations of $\mathrm{SF}_{\text {energy\% }}$ and $\mathrm{SF}_{\text {time }}$ with $\mathrm{BMI}$ and $\mathrm{WC}$ in both men and women. $\mathrm{MF}_{\text {time }}$ was also positively associated with $\mathrm{BMI}$ and $\mathrm{WC}$ in men only, while $\mathrm{MF}_{\text {energy\% }}$ showed no associations in both sexes.

\section{Discussion}

To our knowledge, the present study is the first to examine associations of different measures of MF and SF with dietary intakes and adiposity indices, after taking into account the confounding of energy misreporting. $\mathrm{MF}_{\text {energy } \%}$ was associated with favourable dietary intake patterns in both sexes, while $\mathrm{MF}_{\text {time }}$ showed positive associations with measures of diet quality in women only. In contrast, $\mathrm{SF}_{\text {energy\% }}$ and $\mathrm{SF}_{\text {time }}$ were generally associated with unfavourable dietary intake patterns in both sexes. For adiposity measures, in the multivariate analyses without taking into account EI:EER, all measures of MF and SF showed null associations with BMI and WC in both sexes, with the exception of inverse associations for $\mathrm{MF}_{\text {time }}$ in women. However, after full adjustment including EI:EER, we found positive associations of $\mathrm{SF}_{\text {energy\% }}$ and $\mathrm{SF}_{\text {time }}$ with $\mathrm{BMI}$ and $\mathrm{WC}$ in both sexes. $\mathrm{MF}_{\text {time }}$ was also positively associated with BMI and WC in men. Thus in these analyses, adjustment for EI:EER had a greater impact on the outcomes obtained than did the method of defining meals and snacks. In any case, the present results suggest the different effects of MF and SF on dietary intakes and adiposity measures.

While many epidemiological studies investigating the association between $\mathrm{EF}$ (i.e. sum of $\mathrm{MF}$ and $\mathrm{SF}$ ) and dietary intakes and adiposity measures have yielded inconsistent outcomes ${ }^{(2,6,7,15,21-23)}$, there have been few attempts to investigate the effects of MF and SF separately. For dietary intakes, SF calculated based on self-report was associated with higher intakes of vitamins A, C and E, $\beta$-carotene, $\mathrm{Mg}$ and $\mathrm{K}$ in US elderly people ${ }^{(21)}$. SF calculated based on self-report was also associated with a higher score for the Healthy Eating Index in US adults ${ }^{(22)}$. Conversely, in Swedish adults, SF assessed by a questionnaire showed positive associations with intakes of confectionery, fat, sugar and alcohol, and inverse associations with intakes of protein and dietary fibre ${ }^{(15)}$. This is consistent with our observation in British adults that 
Table 4 Associations of meal frequency and snack frequency with dietary characteristics*; British men aged 19-64 years ( $n$ 678), National Diet and Nutrition Survey, 2000-2001

\begin{tabular}{|c|c|c|c|c|c|c|c|c|c|c|c|c|c|c|}
\hline & \multirow[b]{2}{*}{ Mean } & \multirow[b]{2}{*}{ SD } & \multicolumn{3}{|c|}{$\mathrm{MF}_{\text {energy\% }}($ times/d) $\dagger$} & \multicolumn{3}{|c|}{$\mathrm{SF}_{\text {energy\% }}$ (times/d) $\dagger$} & \multicolumn{3}{|c|}{$\mathrm{MF}_{\text {time }}($ times $/ \mathrm{d}) \ddagger$} & \multicolumn{3}{|c|}{$\mathrm{SF}_{\text {time }}($ times/d)‡ } \\
\hline & & & $\beta \S$ & $\mathrm{SE} \S$ & $P$ & $\beta \S$ & SE§ & $P$ & $\beta \S$ & $\mathrm{SE} \S$ & $P$ & $\beta \S$ & SE§ & $P$ \\
\hline \multicolumn{15}{|l|}{ Food intake (g/10 MJ) } \\
\hline Vegetables & 111.2 & $96 \cdot 4$ & 11.77 & $6 \cdot 43$ & 0.07 & -5.31 & 1.91 & 0.006 & $-4 \cdot 24$ & $3 \cdot 28$ & 0.20 & -8.96 & 3.40 & 0.009 \\
\hline Legumes & 38.5 & $40 \cdot 0$ & -2.24 & 2.79 & 0.42 & -1.14 & 0.83 & 0.17 & -4.32 & 1.41 & 0.002 & 0.43 & 1.48 & 0.77 \\
\hline Fruits & $96 \cdot 2$ & $117 \cdot 4$ & $20 \cdot 10$ & 7.90 & 0.01 & -3.59 & $2 \cdot 36$ & 0.13 & 0.24 & 4.04 & 0.95 & -6.01 & 4.20 & 0.15 \\
\hline Nuts and seeds & $2 \cdot 7$ & 9.5 & 1.08 & 0.68 & 0.11 & -0.27 & 0.20 & 0.18 & -0.24 & 0.34 & 0.48 & -0.30 & 0.36 & 0.40 \\
\hline Cereals & 242.9 & $106 \cdot 2$ & 36.87 & $7 \cdot 34$ & $<0.0001$ & $-15 \cdot 86$ & $2 \cdot 14$ & $<0.0001$ & -16.57 & 3.75 & $<0.0001$ & -22.01 & 3.87 & $<0.0001$ \\
\hline Fish & 34.8 & $41 \cdot 8$ & 0.66 & $2 \cdot 89$ & 0.82 & -2.96 & 0.85 & 0.0005 & -2.92 & 1.46 & 0.046 & -6.05 & 1.51 & $<0.0001$ \\
\hline Meat & 204.7 & $97 \cdot 4$ & -13.98 & $6 \cdot 70$ & 0.04 & -1.11 & 2.00 & 0.58 & $-6 \cdot 13$ & 3.41 & 0.07 & -0.79 & 3.56 & 0.83 \\
\hline Dairy products & 283.0 & $186 \cdot 2$ & 3.15 & $13 \cdot 11$ & 0.81 & 11.45 & 3.87 & 0.003 & 22.41 & $6 \cdot 61$ & 0.0007 & 12.91 & 6.93 & 0.06 \\
\hline Soft drinks & $128 \cdot 1$ & $206 \cdot 1$ & 11.74 & 13.89 & 0.40 & $5 \cdot 28$ & $4 \cdot 13$ & 0.20 & $8 \cdot 11$ & 7.06 & 0.25 & $11 \cdot 26$ & $7 \cdot 35$ & 0.13 \\
\hline Confectionery & 33.1 & 34.1 & -8.75 & 2.38 & 0.0003 & 6.66 & 0.67 & $<0.0001$ & 8.01 & $1 \cdot 18$ & $<0.0001$ & 9.98 & 1.21 & $<0.0001$ \\
\hline Alcoholic beverages & $504 \cdot 7$ & 595.9 & $-294 \cdot 1$ & $40 \cdot 5$ & $<0.0001$ & 113.7 & 11.7 & $<0.0001$ & $109 \cdot 1$ & 21.0 & $<0.0001$ & $160 \cdot 1$ & 21.4 & $<0.0001$ \\
\hline \multicolumn{15}{|l|}{ Nutrient intake } \\
\hline Protein (\% of energy) & $15 \cdot 3$ & 2.9 & 0.20 & 0.19 & 0.31 & -0.27 & 0.06 & $<0.0001$ & -0.33 & $0 \cdot 10$ & 0.0007 & -0.44 & $0 \cdot 10$ & $<0.0001$ \\
\hline Fat (\% of energy) & 33.4 & $5 \cdot 9$ & 1.20 & 0.41 & 0.004 & -1.03 & $0 \cdot 12$ & $<0.0001$ & $-1 \cdot 30$ & 0.21 & $<0.0001$ & -1.52 & 0.21 & $<0.0001$ \\
\hline Saturated fat (\% of energy) & $12 \cdot 5$ & 3.0 & 0.38 & 0.21 & 0.07 & -0.25 & 0.06 & $<0.0001$ & -0.29 & $0 \cdot 11$ & 0.006 & -0.38 & $0 \cdot 11$ & 0.0006 \\
\hline Monounsaturated fat ( $\%$ of energy) & $11 \cdot 2$ & $2 \cdot 3$ & 0.39 & $0 \cdot 16$ & 0.02 & -0.37 & 0.05 & $<0.0001$ & -0.49 & 0.08 & $<0.0001$ & -0.52 & 0.08 & $<0.0001$ \\
\hline Polyunsaturated fat (\% of energy) & $5 . \overline{9}$ & $1 \cdot 7$ & 0.26 & 0.12 & 0.03 & -0.28 & 0.03 & $<0.0001$ & -0.35 & 0.06 & $<0.0001$ & -0.45 & 0.06 & $<0.0001$ \\
\hline Carbohydrate (\% of energy) & 44.7 & $7 \cdot 1$ & 1.81 & 0.50 & 0.0003 & -0.01 & $0 \cdot 15$ & 0.95 & 0.14 & 0.26 & 0.58 & 0.33 & 0.27 & 0.22 \\
\hline Starch (\% of energy) & $25 \cdot 6$ & 5.8 & 2.73 & 0.40 & $<0.0001$ & -1.37 & $0 \cdot 11$ & $<0.0001$ & -1.60 & 0.20 & $<0.0001$ & -1.84 & 0.21 & $<0.0001$ \\
\hline Total sugar ( $\%$ of energy) & $19 \cdot 1$ & $6 \cdot 3$ & -0.92 & 0.44 & 0.04 & 1.36 & $0 \cdot 12$ & $<0.0001$ & 1.74 & 0.22 & $<0.0001$ & $2 \cdot 17$ & 0.22 & $<0.0001$ \\
\hline Non-milk extrinsic sugars ( $\%$ of energy) & $12 \cdot 6$ & $6 \cdot 0$ & -1.69 & 0.41 & $<0.0001$ & 1.45 & 0.11 & $<0.0001$ & 1.68 & 0.20 & $<0.0001$ & $2 \cdot 31$ & 0.20 & $<0.0001$ \\
\hline Alcohol (\% of energy) & $6 \cdot 7$ & $7 \cdot 3$ & -3.23 & 0.50 & $<0.0001$ & 1.32 & $0 \cdot 14$ & $<0.0001$ & 1.50 & 0.26 & $<0.0001$ & 1.65 & 0.27 & $<0.0001$ \\
\hline Dietary fibre (g/10 MJ) & $16 \cdot 0$ & 5.5 & 2.39 & 0.37 & $<0.0001$ & -0.82 & $0 \cdot 11$ & $<0.0001$ & -0.63 & 0.19 & 0.001 & -1.25 & $0 \cdot 19$ & $<0.0001$ \\
\hline Cholesterol (mg/10 MJ) & 312.7 & 115.4 & 2.69 & 8.05 & 0.74 & $-5 \cdot 19$ & $2 \cdot 39$ & 0.03 & $-6 \cdot 50$ & 4.09 & 0.11 & -8.65 & 4.25 & 0.04 \\
\hline \multicolumn{15}{|l|}{ Diet quality score } \\
\hline Healthy Diet Indicatorll & $2 \cdot 27$ & 1.36 & 0.26 & 0.09 & 0.005 & -0.09 & 0.03 & 0.0008 & -0.05 & 0.05 & 0.31 & -0.17 & 0.05 & 0.0005 \\
\hline Mediterranean Diet Scoreף & 4.43 & 1.68 & 0.27 & 0.12 & 0.02 & -0.12 & 0.03 & 0.0004 & -0.11 & 0.06 & 0.06 & -0.19 & 0.06 & 0.002 \\
\hline
\end{tabular}

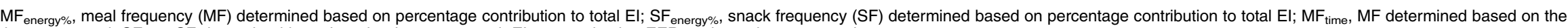
time consumed; $\mathrm{SF}_{\text {time }}$, SF determined based on the time consumed; El, energy intake; EER, estimated energy requirement.

${ }^{*}$ Adjustment was made for age (years, continuous), social class (manual or non-manual) and El:EER (continuous). Statistically significant $P$ values are presented in bold.

†A meal was defined as any eating episode comprising $\geq 15 \%$ of total El, regardless of the time of day or composition of foods and beverages consumed; all other eating episodes were classified as a snack.

¥Meals were defined as eating events reported during selected times of the day (06.00-10.00, 12.00-15.00 and 18.00-21.00 hours); all other eating occasions were considered snacks.

$\S$ Regression coefficients mean the change of dietary variables with one additional eating occasion per day.

IIPossible score ranging from 0 to 7.

IPossible score ranging from 0 to 9 . 
Table 5 Associations of meal frequency and snack frequency with dietary characteristics*; British women aged 19-64 years ( $n$ 809), National Diet and Nutrition Survey, 2000-2001

\begin{tabular}{|c|c|c|c|c|c|c|c|c|c|c|c|c|c|c|}
\hline & \multirow[b]{2}{*}{ Mean } & \multirow[b]{2}{*}{ SD } & \multicolumn{3}{|c|}{$\mathrm{MF}_{\text {energy\% }}($ times/d)† } & \multicolumn{3}{|c|}{$\mathrm{SF}_{\text {energy\% }}($ times $/ \mathrm{d}) \dagger$} & \multicolumn{3}{|c|}{$\mathrm{MF}_{\text {time }}($ times/d)‡ } & \multicolumn{3}{|c|}{$\mathrm{SF}_{\text {time }}($ times/d)‡ } \\
\hline & & & $\beta \S$ & SE§ & $P$ & $\beta \S$ & SE§ & $P$ & $\beta \S$ & SE§ & $P$ & $\beta \S$ & $\mathrm{SE} \S$ & $P$ \\
\hline \multicolumn{15}{|l|}{ Food intake (g/10 MJ) } \\
\hline Vegetables & $162 \cdot 0$ & $123 \cdot 0$ & $15 \cdot 63$ & 7.44 & 0.04 & -3.88 & $3 \cdot 13$ & 0.22 & $12 \cdot 60$ & 5.00 & 0.01 & $-18 \cdot 28$ & 5.42 & 0.0008 \\
\hline Legumes & 35.9 & $40 \cdot 0$ & 2.38 & 2.48 & 0.34 & $-2 \cdot 12$ & 1.04 & 0.04 & -0.49 & 1.67 & 0.77 & -4.58 & 1.81 & 0.01 \\
\hline Fruits & $155 \cdot 7$ & 171.9 & $14 \cdot 16$ & $10 \cdot 12$ & 0.16 & $5 \cdot 50$ & 4.25 & 0.20 & 33.51 & $6 \cdot 72$ & $<0.0001$ & $-15 \cdot 29$ & 7.39 & 0.04 \\
\hline Nuts and seeds & $2 \cdot 7$ & 9.9 & 0.53 & 0.62 & 0.39 & -0.16 & 0.26 & 0.52 & -0.11 & 0.41 & 0.80 & -0.09 & 0.45 & 0.84 \\
\hline Cereals & 241.7 & $103 \cdot 7$ & $27 \cdot 70$ & 6.34 & $<0.0001$ & -16.04 & 2.63 & $<0.0001$ & -9.47 & 4.30 & 0.03 & -22.69 & 4.62 & $<0.0001$ \\
\hline Fish & 44.9 & 58.7 & 3.91 & 3.55 & 0.27 & -2.00 & 1.49 & 0.18 & 1.65 & $2 \cdot 39$ & 0.49 & -5.94 & 2.59 & 0.02 \\
\hline Meat & $188 \cdot 3$ & $113 \cdot 8$ & $-4 \cdot 81$ & 6.83 & 0.48 & -6.03 & $2 \cdot 86$ & 0.04 & -9.72 & 4.59 & 0.03 & -9.40 & 4.98 & 0.06 \\
\hline Dairy products & $365 \cdot 6$ & 221.8 & $-13 \cdot 27$ & 13.54 & 0.33 & $19 \cdot 19$ & 5.65 & 0.0007 & 26.72 & 9.07 & 0.003 & $19 \cdot 60$ & 9.88 & 0.048 \\
\hline Soft drinks & 127.5 & $216 \cdot 2$ & -22.07 & 12.91 & 0.09 & 23.23 & $5 \cdot 36$ & $<0.0001$ & $17 \cdot 81$ & 8.68 & 0.04 & 37.66 & $9 \cdot 36$ & $<0.0001$ \\
\hline Confectionery & 31.3 & 34.4 & -2.07 & 2.09 & 0.32 & 6.84 & 0.84 & $<0.0001$ & $7 \cdot 27$ & 1.38 & $<0.0001$ & 11.07 & 1.48 & $<0.0001$ \\
\hline Alcoholic beverages & $205 \cdot 7$ & $358 \cdot 3$ & $-126 \cdot 9$ & 21.5 & $<0.0001$ & 78.5 & 8.8 & $<0.0001$ & 44.6 & 14.7 & 0.003 & $117 \cdot 7$ & $15 \cdot 5$ & $<0.0001$ \\
\hline \multicolumn{15}{|l|}{ Nutrient intake } \\
\hline Protein (\% of energy) & $15 \cdot 9$ & $3 \cdot 3$ & 0.40 & 0.18 & 0.025 & -0.41 & 0.07 & $<0.0001$ & -0.15 & $0 \cdot 12$ & 0.23 & -0.85 & 0.13 & $<0.0001$ \\
\hline Fat (\% of energy) & 33.6 & $6 \cdot 6$ & 0.54 & 0.40 & 0.18 & -1.43 & 0.16 & $<0.0001$ & -2.05 & 0.26 & $<0.000$ & -1.63 & 0.29 & $<0.0001$ \\
\hline o of energy) & $12 \cdot 7$ & 3.3 & 0.26 & 0.20 & 0.20 & -0.41 & 0.08 & $<0.0001$ & -0.54 & 0.13 & $<0.0001$ & -0.47 & 0.15 & 0.001 \\
\hline Monounsaturated fat ( $\%$ of energy) & $11 \cdot 0$ & 2.5 & 0.08 & 0.16 & 0.60 & -0.53 & 0.06 & $<0.0001$ & -0.82 & $0 \cdot 10$ & $<0.0001$ & -0.58 & 0.11 & $<0.0001$ \\
\hline Polyunsaturated fat (\% of energy) & $6 \cdot 1$ & 1.7 & 0.08 & 0.11 & 0.46 & -0.32 & 0.04 & $<0.0001$ & -0.45 & 0.07 & $<0.0001$ & -0.40 & 0.08 & $<0.0001$ \\
\hline Carbohydrate ( $\%$ of energy) & $46 \cdot 5$ & $7 \cdot 1$ & 0.58 & 0.44 & 0.19 & 0.70 & $0 \cdot 18$ & 0.0002 & 1.22 & 0.30 & $<0.0001$ & 0.99 & 0.32 & 0.002 \\
\hline Starch (\% of energy) & 26.5 & $5 \cdot 8$ & 1.22 & 0.35 & 0.0005 & -1.33 & 0.14 & $<0.0001$ & -1.55 & 0.23 & $<0.0001$ & -1.56 & 0.25 & $<0.0001$ \\
\hline Total sugar (\% of energy) & $20 \cdot 0$ & $6 \cdot 6$ & -0.64 & 0.40 & 0.11 & 2.03 & $0 \cdot 15$ & $<0.0001$ & 2.77 & 0.25 & $<0.0001$ & 2.55 & 0.28 & $<0.0001$ \\
\hline Non-milk extrinsic sugars ( $\%$ of energy) & 11.4 & $6 \cdot 1$ & -1.09 & 0.36 & 0.003 & 1.88 & 0.14 & $<0.0001$ & 1.96 & 0.23 & $<0.0001$ & $2 \cdot 82$ & 0.24 & $<0.0001$ \\
\hline Alcohol (\% of energy) & 4.0 & 5.5 & -1.56 & 0.34 & $<0.0001$ & $1 \cdot 15$ & $0 \cdot 14$ & $<0.0001$ & 0.97 & 0.23 & $<0.0001$ & 1.50 & 0.24 & $<0.0001$ \\
\hline Dietary fibre (g/10 MJ) & $18 \cdot 7$ & $7 \cdot 1$ & 1.69 & 0.42 & $<0.0001$ & -0.61 & 0.18 & 0.0005 & 0.49 & 0.28 & 0.09 & -1.52 & 0.30 & $<0.0001$ \\
\hline Cholesterol (mg/10 MJ) & 314.9 & $125 \cdot 6$ & 21.99 & 7.57 & 0.004 & $-12 \cdot 43$ & $3 \cdot 16$ & $<0.0001$ & $-5 \cdot 80$ & $5 \cdot 11$ & 0.26 & $-19 \cdot 13$ & $5 \cdot 52$ & 0.0006 \\
\hline \multicolumn{15}{|l|}{ Diet quality score } \\
\hline Healthy Diet Indicatorll & 2.51 & 1.34 & 0.12 & 0.08 & $0 \cdot 13$ & -0.02 & 0.03 & 0.52 & 0.12 & 0.06 & 0.03 & -0.15 & 0.06 & 0.02 \\
\hline Mediterranean Diet Scoreף & 4.39 & 1.67 & 0.27 & 0.10 & 0.008 & -0.11 & 0.04 & 0.008 & 0.14 & 0.07 & 0.047 & -0.36 & 0.07 & $<0.0001$ \\
\hline
\end{tabular}

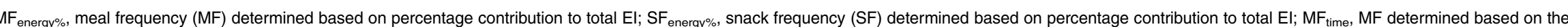
time consumed; $\mathrm{SF}_{\text {time }}$, SF determined based on the time consumed; El, energy intake; EER, estimated energy requirement.

"Adjustment was made for age (years, continuous), social class (manual or non-manual) and El:EER (continuous). Statistically significant $P$ values are presented in bold.

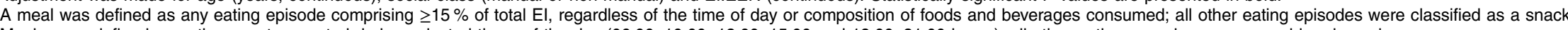
(

Regression coefficients mean the change of dietary variables with one additional eating occasion per day.

TPosible score ranging from 0 to 7 . 
Table 6 Associations of meal frequency and snack frequency with adiposity measures ${ }^{\star}$; British adults aged 19-64 years ( $n$ 1487), National Diet and Nutrition Survey, 2000-2001

\begin{tabular}{|c|c|c|c|c|c|c|c|c|c|}
\hline & \multicolumn{3}{|c|}{ Model 1† } & \multicolumn{3}{|c|}{ Model $2 \ddagger$} & \multicolumn{3}{|c|}{ Model $3 \S$} \\
\hline & $\beta \|$ & SEll & $P$ & $\beta \|$ & SEll & $P$ & $\beta \|$ & SEll & $P$ \\
\hline \multicolumn{10}{|c|}{ Men ( $n$ 678) } \\
\hline \multicolumn{10}{|c|}{$\mathrm{MF}_{\text {energy\% }}$ (times $\left./ \mathrm{d}\right) \boldsymbol{\Phi}$} \\
\hline $\mathrm{BMI}\left(\mathrm{kg} / \mathrm{m}^{2}\right)$ & -0.18 & 0.30 & 0.54 & -0.58 & 0.31 & 0.06 & -0.28 & 0.31 & 0.36 \\
\hline WC $(\mathrm{cm})$ & -0.02 & 0.77 & 0.98 & $-1 \cdot 14$ & 0.77 & 0.14 & -0.51 & 0.77 & 0.51 \\
\hline \multicolumn{10}{|c|}{$\mathrm{SF}_{\text {energy\% }}$ (times/d)ף } \\
\hline BMI $\left(\mathrm{kg} / \mathrm{m}^{2}\right)$ & -0.22 & 0.08 & 0.0006 & -0.01 & $0 \cdot 10$ & 0.94 & 0.32 & 0.11 & 0.003 \\
\hline WC $(\mathrm{cm})$ & -0.48 & 0.21 & 0.02 & 0.06 & 0.24 & 0.81 & 0.77 & 0.27 & 0.004 \\
\hline \multicolumn{10}{|c|}{$\mathrm{MF}_{\text {time }}(\text { times } / \mathrm{d})^{\star *}$} \\
\hline BMI $\left(\mathrm{kg} / \mathrm{m}^{2}\right)$ & -0.32 & 0.14 & 0.02 & -0.09 & 0.15 & 0.57 & 0.33 & 0.16 & 0.04 \\
\hline WC $(\mathrm{cm})$ & -0.55 & 0.36 & $0 \cdot 12$ & -0.06 & 0.37 & 0.86 & 0.85 & 0.40 & 0.03 \\
\hline \multicolumn{10}{|c|}{$\mathrm{SF}_{\text {time }}(\text { times } / \mathrm{d})^{\star *}$} \\
\hline BMI $\left(\mathrm{kg} / \mathrm{m}^{2}\right)$ & -0.42 & 0.15 & 0.005 & -0.08 & 0.17 & 0.63 & 0.36 & 0.18 & 0.04 \\
\hline WC $(\mathrm{cm})$ & -0.96 & 0.37 & 0.01 & -0.08 & 0.41 & 0.85 & 0.87 & 0.44 & 0.047 \\
\hline \multicolumn{10}{|c|}{ Women (n 809) } \\
\hline \multicolumn{10}{|c|}{$\mathrm{MF}_{\text {energy\% }}$ (times/d) } \\
\hline BMI $\left(\mathrm{kg} / \mathrm{m}^{2}\right)$ & 0.03 & 0.34 & 0.92 & -0.22 & 0.35 & 0.53 & 0.18 & 0.34 & 0.59 \\
\hline WC $(\mathrm{cm})$ & -0.41 & 0.73 & 0.58 & -0.48 & 0.73 & 0.51 & 0.25 & 0.71 & 0.73 \\
\hline \multicolumn{10}{|c|}{$\mathrm{SF}_{\text {eneray\% }}$ (times $\left./ \mathrm{d}\right) \mathscr{I}$} \\
\hline $\operatorname{BMl}\left(\mathrm{kg} / \mathrm{m}^{2}\right)$ & -0.37 & 0.13 & 0.004 & -0.20 & 0.15 & 0.21 & 0.40 & 0.17 & 0.02 \\
\hline WC $(\mathrm{cm})$ & -0.61 & 0.27 & 0.03 & -0.38 & 0.32 & 0.23 & 0.69 & 0.35 & 0.048 \\
\hline \multicolumn{10}{|c|}{$\mathrm{MF}_{\text {time }}(\text { times } / \mathrm{d})^{\star *}$} \\
\hline BMI $\left(\mathrm{kg} / \mathrm{m}^{2}\right)$ & -0.63 & 0.20 & 0.002 & -0.57 & 0.23 & 0.01 & 0.23 & 0.24 & 0.34 \\
\hline WC $(\mathrm{cm})$ & -1.54 & 0.43 & 0.0003 & -1.46 & 0.47 & 0.002 & -0.10 & 0.52 & 0.85 \\
\hline \multicolumn{10}{|c|}{$\mathrm{SF}_{\text {time }}(\text { times } / \mathrm{d})^{\star *}$} \\
\hline $\mathrm{BMI}\left(\mathrm{kg} / \mathrm{m}^{2}\right)$ & -0.37 & 0.23 & 0.11 & 0.07 & 0.26 & 0.80 & 0.88 & 0.27 & 0.001 \\
\hline WC $(\mathrm{cm})$ & -0.17 & 0.49 & 0.73 & 0.55 & 0.55 & 0.32 & 2.09 & 0.56 & 0.0002 \\
\hline
\end{tabular}

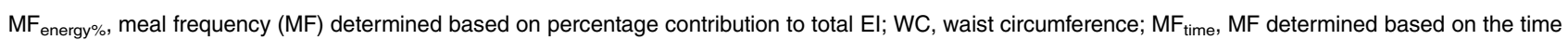

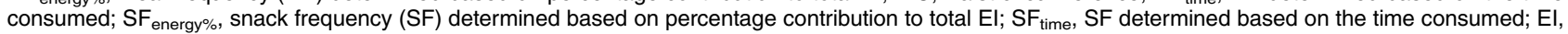
energy intake; MET, metabolic equivalents of task; ERR, estimated energy requirement.

* Statistically significant $P$ values are presented in bold.

†Crude model.

$\ddagger$ Adjusted for age (years, continuous), social class (manual or non-manual), smoking status (never, former, or current), physical activity (MET-h/d, continuous), protein intake (\% of energy, continuous), fat intake (\% of energy, continuous), total sugar intake (\% of energy, continuous), alcohol intake (\% of energy, continuous) and dietary fibre intake ( $\mathrm{g} / 10 \mathrm{MJ}$, continuous).

§Adjusted for variables used in model 2 and EI:EER (continuous).

IIRegression coefficients mean the change of adiposity measures with one additional eating occasion per day.

IA meal was defined as any eating episode comprising $\geq 15 \%$ of total El, regardless of the time of day or composition of foods and beverages consumed; all other eating episodes were classified as a snack.

${ }^{* *}$ Meals were defined as eating events reported during selected times of the day $(06.00-10.00,12.00-15.00$ and $18.00-21.00$ hours); all other eating occasions were considered snacks.

$\mathrm{SF}_{\text {energy } \%}$ and $\mathrm{SF}_{\text {time }}$ were associated with unfavourable dietary intake patterns, including higher intakes of soft drinks, confectionery and alcohol, lower intakes of cereals, protein, fat, and dietary fibre, and lower scores of

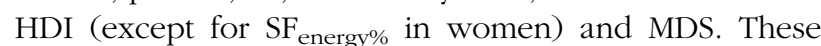
discrepant findings may be, at least partly, explained by differences in the characteristics and lifestyles of the populations, definitions of SF, dietary assessment methods and potential confounding factors considered. While we are unaware of previous studies where the association between MF and dietary intake was examined, we found

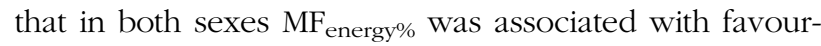
able dietary intake patterns, including higher intakes of vegetables, fruits and dietary fibre, lower intakes of nonmilk extrinsic sugars and alcohol, and higher scores of HDI (only men) and MDS, while $\mathrm{MF}_{\text {time }}$ was associated with higher scores of HDI and MDS in women only. These results highlight how the use of different definitions of meals and snacks can impact the outcomes. For adiposity measures, a cross-sectional study in US adults ${ }^{(19)}$ has shown that after excluding implausible energy reporters, $\mathrm{SF}$, but not MF, as defined mainly based on self-report and energy content, was positively associated with BMI. Despite the use of different definitions of meals and snacks, this is generally consistent with our observation that $\mathrm{SF}_{\text {energy\%, }} \mathrm{SF}_{\text {time }}$ and $\mathrm{MF}_{\text {time }}$ (men only), but not

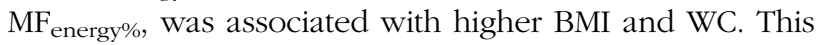
seems plausible given the modest positive association of $\mathrm{SF}_{\text {energy\% }}, \mathrm{SF}_{\text {time }}$ and $\mathrm{MF}_{\text {time }}$ with EI. On the other hand, $\mathrm{MF}_{\text {energy\% }}$ was only weakly (but significantly) associated with EI, showing no association with BMI and WC. In any case, the positive association of $\mathrm{MF}$ and SF with EI suggests that participants in the present study did not compensate for more frequent eating episodes by reducing the quantity of energy consumed per eating occasion.

In the present study, (the direction of) the association of MF and SF with BMI and WC changed radically after adjustment for EI:EER. Given the positive association 
of MF and SF with EI:EER and the inverse association of BMI and WC with EI:EER, this may be due to the underreporting of MF and SF concomitant with the underreporting of EI by individuals with higher BMI and $\mathrm{WC}^{(20)}$. Thus, the present study highlights the key importance of adjusting for EI misreporting in studies of MF and SF in relation to adiposity measures.

The strengths of our study include the use of objective and published definitions of MF and SF based on detailed dietary information obtained from a $7 \mathrm{~d}$ weighed dietary record, measured anthropometric data and the use of an individualized measure of EER to identify EI misreporters. However, there are also several limitations. First, the cross-sectional nature of the study does not permit the assessment of causality owing to the uncertain temporality of the association. Many health organizations, diet books and Internet sites recommend eating small, frequent meals for weight loss. Because of this, overweight and obese individuals may increase their MF, although it is unlikely in the present study that they eat small meals given the positive correlation between MF and EI observed. Alternatively, overweight and obese individuals may simply have reduced their MF and SF in an attempt to lose weight. If so the strength of the positive association between MF and SF and adiposity measures would be underestimated. In any case, only a prospective study taking into account dietary misreporting would provide better understanding of the relationship between MF and SF and adiposity measures.

At present, the only way to obtain unbiased information on energy requirements in free-living settings is to use doubly labelled water as a biomarker ${ }^{(42)}$. This technique is expensive and impractical for application to large-scale epidemiological studies. Instead, we calculated EER with the use of published equations ${ }^{(36)}$. In the absence of measured total energy expenditure, these equations with high $R^{2}$ values $(0.82 \text { for men and } 0.79 \text { for women })^{(36)}$ should serve as the best proxy, although the selection of physical activity category was based on self-report (i.e. $7 \mathrm{~d}$ physical activity diary), which may be susceptible to reporting bias.

Another limitation of the present study is the relatively low response rate $(61 \%)$, and only $40 \%$ of the eligible sample was included in the present study. The participants included in the present analysis ( $n$ 1487) differed somewhat from those excluded from the analysis ( $n$ 705-758 depending on variables). Those excluded were more likely to be younger, be in manual occupations and be current smokers (all $P<0 \cdot 05$ ). However, a previous analysis concluded that there was no evidence to suggest serious non-response bias in $\mathrm{NDNS}^{(26)}$. Further, although we adjusted for a variety of potential confounding variables, residual confounding could not be ruled out.

Finally, because only EF of meals contributing $\geq 15 \%$ of total EI (i.e. $\mathrm{MF}_{\text {energy\%) }}$ showed null associations with $\mathrm{BMI}$ and WC (as well as positive associations of $\mathrm{MF}_{\text {time, }}$,
$\mathrm{SF}_{\text {energy\% }}$ and $\mathrm{SF}_{\text {time }}$ with $\mathrm{BMI}$ and $\mathrm{WC}$ ), the present findings should not be interpreted as conclusive evidence that eating less frequently (e.g. one or two large meals per day) is an effective way to prevent obesity but that higher SF or EF of additional small meals may be a contributing factor to obesity. Nevertheless, oversimplification should be avoided because there is no consensus about what constitutes a snack or a meal. As mentioned above, we could not conduct the present analysis based on self-identification of eating occasions, the most common definition of meals and snacks, because of a lack of information in NDNS. Additionally, MF and SF based on time may be problematic, because eating patterns vary according to lifestyle (e.g. shift workers, individuals who consistently eat their meals at non-traditional times of day) as well as the cultural environment ${ }^{(25)}$. Furthermore, MF and SF based on energy contribution $(\geq 15 \%$ or $<15 \%)$ was made on the basis of the US national averages of the distribution of energy from (self-defined) meals compared with (self-defined) snacks (breakfast, $\approx 16 \%$; lunch, $\approx 25 \%$; dinner, $\approx 37 \%$; snacks, $\approx 22 \%$ from two occasions) ${ }^{(43)}$, but this may not be suitable in the present British population. Thus, results may possibly differ on the basis of other definitions. In any case, as research explicitly examining the impact of these different definitions is limited, further research using different definitions of meals and snacks is warranted.

\section{Conclusion}

In the current cross-sectional study in British adults, after taking into account the confounding of EI misreporting, $\mathrm{MF}_{\text {energy\% }}$ was associated with favourable dietary intake patterns in both sexes, while $\mathrm{MF}_{\text {time }}$ showed positive associations with measures of diet quality in women only. Conversely, $\mathrm{SF}_{\text {energy\% }}$ and $\mathrm{SF}_{\text {time }}$ were generally associated with unfavourable dietary intake patterns in both sexes. For adiposity measures, we found positive associations of $\mathrm{SF}_{\text {energy\% }}$ and $\mathrm{SF}_{\text {time }}$ with $\mathrm{BMI}$ and WC in both sexes, which was not observed when EI:EER was not entered in the model. $\mathrm{MF}_{\text {time }}$ was also positively associated with BMI and WC in men. The present results thus suggest the different effects of MF and SF on dietary intake and adiposity measures, as well as the importance of adjustment for EI: EER. Further research, particularly with a prospective design, is needed, taking into account dietary misreporting so that firm conclusions can be drawn with regard to the effect of MF and SF on dietary intakes and adiposity measures.

\section{Acknowledgements}

Financial support: This work was supported in part by the Grants-in-Aid for Young Scientists (B) from the Ministry of 
Education, Culture, Sports, Science and Technology of Japan (K.M., grant number 15K16213). The Ministry of Education, Culture, Sports, Science and Technology of Japan had no role in the design, analysis or writing of this article. Conflict of interest: None. Authorship: K.M. contributed to the concept and design of the study, statistical analysis, data interpretation and manuscript writing. M.B.E.L. critically reviewed the manuscript. Both authors read and approved the final manuscript. Ethics of human subject participation: This study was conducted according to the guidelines laid down in the Declaration of Helsinki and all procedures involving human subjects were approved by the National Health Service Local Research Ethics Committee covering each of the postal sectors. Written informed consent was obtained from all participants.

\section{Supplementary material}

To view supplementary material for this article, please visit http://dx.doi.org/10.1017/S1368980015002979

\section{References}

1. Drummond SE, Crombie NE, Cursiter MC et al. (1998) Evidence that eating frequency is inversely related to body weight status in male, but not female, non-obese adults reporting valid dietary intakes. Int J Obes Relat Metab Disord 22, 105-112.

2. Titan SM, Bingham S, Welch A et al. (2001) Frequency of eating and concentrations of serum cholesterol in the Norfolk population of the European prospective investigation into cancer (EPIC-Norfolk): cross sectional study. BMJ 323, $1286-1288$.

3. Ruidavets JB, Bongard V, Bataille V et al. (2002) Eating frequency and body fatness in middle-aged men. Int J Obes Relat Metab Disord 26, 1476-1483.

4. Ma Y, Bertone ER, Stanek EJ 3rd et al. (2003) Association between eating patterns and obesity in a free-living US adult population. Am J Epidemiol 158, 85-92.

5. Marin-Guerrero AC, Gutierrez-Fisac JL, Guallar-Castillon P et al. (2008) Eating behaviours and obesity in the adult population of Spain. Br J Nutr 100, 1142-1148.

6. Holmback I, Ericson U, Gullberg B et al. (2010) A high eating frequency is associated with an overall healthy lifestyle in middle-aged men and women and reduced likelihood of general and central obesity in men. Br J Nutr 104, $1065-1073$.

7. Smith KJ, Blizzard L, McNaughton SA et al. (2012) Daily eating frequency and cardiometabolic risk factors in young Australian adults: cross-sectional analyses. Br J Nutr 108, 1086-1094.

8. Kant AK, Schatzkin A, Graubard BI et al. (1995) Frequency of eating occasions and weight change in the NHANES I Epidemiologic Follow-up Study. Int J Obes Relat Metab Disord 19, 468-474.

9. Summerbell CD, Moody RC, Shanks J et al. (1996) Relationship between feeding pattern and body mass index in 220 free-living people in four age groups. Eur J Clin Nutr 50, 513-519.

10. Duval K, Strychar I, Cyr MJ et al. (2008) Physical activity is a confounding factor of the relation between eating frequency and body composition. Am J Clin Nutr 88, 1200-1205.
11. Berg C, Lappas G, Wolk A et al. (2009) Eating patterns and portion size associated with obesity in a Swedish population. Appetite 52, 21-26.

12. Hartline-Grafton HL, Rose D, Johnson CC et al. (2010) The influence of weekday eating patterns on energy intake and BMI among female elementary school personnel. Obesity (Silver Spring) 18, 736-742.

13. Mills JP, Perry CD \& Reicks M (2011) Eating frequency is associated with energy intake but not obesity in midlife women. Obesity (Silver Spring) 19, 552-559.

14. Berteus Forslund H, Lindroos AK, Sjostrom L et al. (2002) Meal patterns and obesity in Swedish women - a simple instrument describing usual meal types, frequency and temporal distribution. Eur J Clin Nutr 56, 740-747.

15. Berteus Forslund H, Torgerson JS, Sjostrom L et al. (2005) Snacking frequency in relation to energy intake and food choices in obese men and women compared to a reference population. Int J Obes Relat Metab Disord 29, 711-719.

16. Huang TT, Roberts SB, Howarth NC et al. (2005) Effect of screening out implausible energy intake reports on relationships between diet and BMI. Obes Res 13, 1205-1217.

17. Yannakoulia M, Melistas L, Solomou E et al. (2007) Association of eating frequency with body fatness in pre- and postmenopausal women. Obesity (Silver Spring) 15, 100-106.

18. van der Heijden AA, Hu FB, Rimm EB et al. (2007) A prospective study of breakfast consumption and weight gain among US men. Obesity (Silver Spring) 15, 2463-2469.

19. Howarth NC, Huang TTK, Roberts SB et al. (2007) Eating patterns and dietary composition in relation to BMI in younger and older adults. Int J Obes (Lond) 31, 675-684.

20. Murakami K \& Livingstone MBE (2014) Eating frequency in relation to body mass index and waist circumference in British adults. Int J Obes (Lond) 38, 1200-1206.

21. Zizza CA, Arsiwalla DD \& Ellison KJ (2010) Contribution of snacking to older adults' vitamin, carotenoid, and mineral intakes. J Am Diet Assoc 110, 768-772.

22. Zizza CA \& Xu B (2012) Snacking is associated with overall diet quality among adults. J Acad Nutr Diet 112, 291-296.

23. Leech RM, Worsley A, Timperio A et al. (2015) Understanding meal patterns: definitions, methodology and impact on nutrient intake and diet quality. Nutr Res Rev 28, 1-21.

24. Chapelot D (2011) The role of snacking in energy balance: a biobehavioral approach. J Nutr 141, 158-162.

25. Johnson GH \& Anderson GH (2010) Snacking definitions: impact on interpretation of the literature and dietary recommendations. Crit Rev Food Sci Nutr 50, 848-871.

26. Food Standards Agency (2010) NDNS previous survey reports. http://webarchive.nationalarchives.gov.uk/20100406130654/ http://food.gov.uk/science/dietarysurveys/ndnsdocuments/ ndnsprevioussurveyreports/ (accessed August 2012).

27. Murakami K, McCaffrey TA \& Livingstone MBE (2013) Associations of dietary glycaemic index and glycaemic load with food and nutrient intake and general and central obesity in British adults. Br J Nutr 110, 2047-2057.

28. Smithers G (1993) MAFF's nutrient databank. Nutr Food Sci 93, $16-19$

29. Food Standards Agency (2002) McCance \& Widdowson's The Composition of Foods, 6th ed. Cambridge: Royal Society of Chemistry.

30. Huijbregts P, Feskens E, Rasanen L et al. (1997) Dietary pattern and 20 year mortality in elderly men in Finland, Italy, and The Netherlands: longitudinal cohort study. BMJ 315, 13-17.

31. Struijk EA, Beulens JW, May AM et al. (2014) Dietary patterns in relation to disease burden expressed in disabilityadjusted life years. Am J Clin Nutr 100, 1158-1165.

32. Trichopoulou A, Orfanos P, Norat T et al. (2005) Modified Mediterranean diet and survival: EPIC-elderly prospective cohort study. BMJ 330, 991. 
33. Ritchie LD (2012) Less frequent eating predicts greater BMI and waist circumference in female adolescents. Am J Clin Nutr 95, 290-296.

34. Duffey KJ, Pereira RA \& Popkin BM (2013) Prevalence and energy intake from snacking in Brazil: analysis of the first nationwide individual survey. Eur J Clin Nutr 67, 868-874.

35. Ainsworth BE, Haskell WL, Herrmann SD et al. (2011) 2011 Compendium of Physical Activities: a second update of codes and MET values. Med Sci Sports Exerc 43, 1575-1581.

36. Institute of Medicine (2002) Dietary Reference Intakes for Energy, Carbohydrate, Fiber, Fat, Fatty Acids, Cholesterol, Protein and Amino Acids. Washington, DC: National Academy Press.

37. World Health Organization (2000) Obesity: Preventing and Managing the Global Epidemic. Report of a WHO Consultation. WHO Technical Report Series no. 894. Geneva: WHO.

38. Jennings A, Cassidy A, van Sluijs EM et al. (2012) Associations between eating frequency, adiposity, diet, and activity in
9-10 year old healthy-weight and centrally obese children. Obesity (Silver Spring) 20, 1462-1468.

39. Johnson L, Mander AP, Jones LR et al. (2007) Is sugarsweetened beverage consumption associated with increased fatness in children? Nutrition 23, 557-563.

40. McCaffrey TA, Rennie KL, Kerr MA et al. (2008) Energy density of the diet and change in body fatness from childhood to adolescence; is there a relation? Am J Clin Nutr $\mathbf{8 7}$, 1230-1237.

41. Kelly MT, Rennie KL, Wallace JM et al. (2009) Associations between the portion sizes of food groups consumed and measures of adiposity in the British National Diet and Nutrition Survey. Br J Nutr 101, 1413-1420.

42. Livingstone MBE \& Black AE (2003) Markers of the validity of reported energy intake. J Nutr 133, Suppl. 3, 895S-920S.

43. Kant AK \& Graubard BI (2015) 40-year trends in meal and snack eating behaviors of American adults. J Acad Nutr Diet 115, 50-63. 